\title{
Microhomology-mediated end joining: new players join the team
}

\author{
Hailong Wang ${ }^{1 *}$ and Xingzhi $X u^{1,2^{*}}$
}

\begin{abstract}
DNA double-strand breaks (DSBs) are the most deleterious type of DNA damage in cells arising from endogenous and exogenous attacks on the genomic DNA. Timely and properly repair of DSBs is important for genomic integrity and survival. MMEJ is an error-prone repair mechanism for DSBs, which relies on exposed microhomologous sequence flanking broken junction to fix DSBs in a Ku- and ligase IV-independent manner. Recently, significant progress has been made in MMEJ mechanism study. In this review, we will summarize its biochemical activities of several newly identified MMEJ factors and their biological significance.
\end{abstract}

Keywords: DNA double-strand breaks (DSBs), Microhomology-mediated end joining (MMEJ), End resection, RPA,

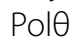

\section{Background}

Double-strand breaks (DSBs) are potentially lethal lesions that arise from endogenous and exogenous genotoxic agents [1, 2]. Unrepaired DSBs cause chromosome breaks and translocations that are associated with developmental defects, neurodegeneration, immunodeficiency, radiosensitivity, sterility, and cancer predisposition [3-5]. Non-homologous end joining (NHEJ) and homologous recombination (HR)-mediated DSB repair are two major pathways to fix DSBs [6, 7]. HR is generally considered to be an error-free mechanism because the identical sister chromatids are used as templates to repair DSBs when cells reside at the $\mathrm{S}$ and $\mathrm{G} 2$ phases. Ku-dependent classical non-homologous end joining (C-NHEJ) is active in all phases of the cell cycle, which can be high fidelity or associate with small alterations at junction since direct end ligation is catalyzed by DNA ligase IV [8-10]. In the absence of $\mathrm{Ku}$ protein or in C-NHEJ-deficient cells, resection machinery will expose extensive single strand DNA (ssDNA) which allows cells to use alternative end join (A-NHEJ) or HR as repair mechanism. A subset

\footnotetext{
*Correspondence: Hailwang@cnu.edu.cn; Xingzhi.Xu@szu.edu.cn

${ }^{1}$ Beijing Key Laboratory of DNA Damage Response and College of Life

Sciences, Capital Normal University, Beijing 100048, China

${ }^{2}$ Shenzhen University School of Medicine, Shenzhen 518060,

Guangdong, China
}

of A-NHEJ relies on microhomologous sequences on either side of the DSB, thus is named as microhomology-mediated end joining (MMEJ) [10-12]. MMEJ is a mutagenic DSB repair mechanism, which always associates with deletions flanking the break sites and contributes to chromosome translocations and rearrangements. Recent study indicated that MMEJ is used with appreciable frequency even when HR is available [13]. It seems that MMEJ is a crucial DSB repair mechanism for HRdefective tumors [14]. These raised the possibility that MMEJ may not just is a back-up repair mechanism. The molecular mechanism of MMEJ thus draws much attention in the field. Several important MMEJ factors have been identified recently [14-17]. Here, we will discuss biochemical properties and regulatory mechanism of these pivotal factors in MMEJ repair.

\section{Basic mechanisms of MMEJ}

As shown in Fig. 1, the proposed MMEJ model involves at least five steps: resection of the DSB ends, annealing of microhomologous region, removal of heterologous flaps, fill-in synthesis and ligation [17-21]. Resembling to HRmediated DSB repair, a certain degree of end resection is also needed for MMEJ. MMEJ and HR may share the initial end resection step in DSB repair [13]. HR requires extensive end resection to recruit Rad51 recombinase 


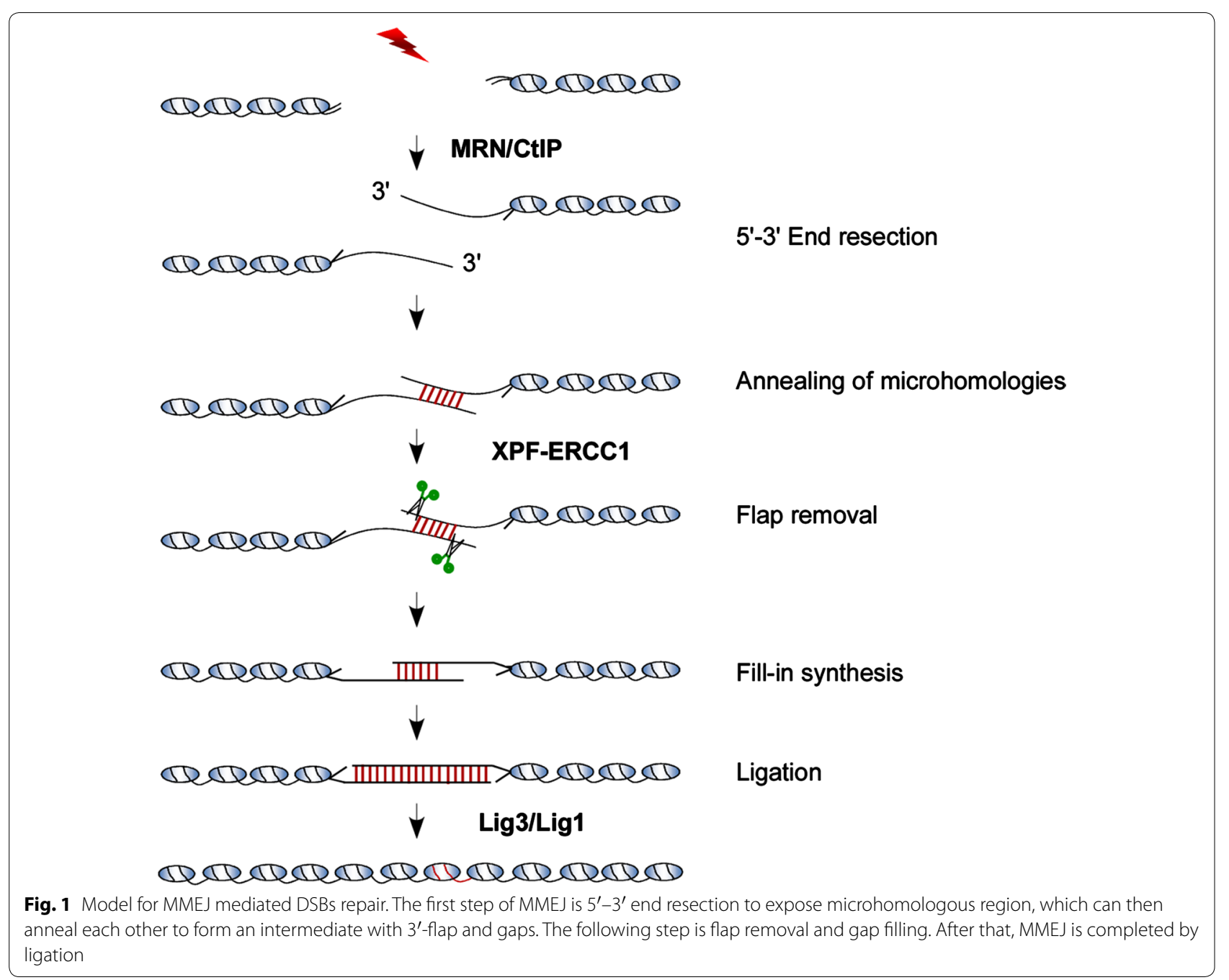

and initiate homologous pairing while limited end resection is sufficient for exposing of microhomologous region and thus promoting MMEJ, Following end resection, the exposed microhomologous sequence will be annealed to form an intermediate with 3 -flap and gaps on both sides of the DSB. So far, we still do not quite clear the exactly mechanism by which microhomologous sequences move close and perform annealing. It may start with a thermodynamically-driven fashion and be regulated with some proteins factors or enzymes [16, 22]. After microhomologous annealing, the no-homologous $3^{\prime}$ tail ( $3^{\prime}$-heterologous flaps) must be removed to allow DNA polymerase to fill-in the gap and stabilize the annealed intermediate. Usually, this step is executed by substrate structure specific endonuclease, such as XPF/ERCC1 in mammals. The final step of MMEJ is DNA ligase III/I (Lig3/Lig1) mediated break end ligation. Obviously, after MMEJ-mediated repair, a significant part of sequence was removed from original DNA. Therefore, in nature, MMEJ is an errorprone DSB repair pathway (Fig. 1).

\section{Resection factors: mechanisms are still missing}

In principle, both $\mathrm{HR}$ and MMEJ are initiated by $5^{\prime}-3^{\prime}$ resection of DSB ends to expose ssDNA overhangs. While HR needs a long 3 '-ssDNA tail to invade homologous template, MMEJ requires exposure of two microhomologous regions to anneal each other. Studies in yeast and mammalian cells indicated that DSB end resection may be carried out in two steps: Mre11 complex and Sae2/CtIP remove covalent adducts, such as bound proteins and hairpin-capped ends and initiate end resection. Sgs1/Exo1 and DNA2 in yeast or BLM (human homologue of Sgs1) and Exo1 in human cells take over to produce extended $3^{\prime}$-ssDNA tail [23-28]. It has been demonstrated that both Mre11 and CtIP are important for MMEJ. However, depletion of long-range resection 
factors including BLM/Exo1 in mammalian cells and Sgs1/Exo1 in yeast significantly increased frequency of MMEJ when the microhomologous regions close to the break site [13, 16, 29]. Possibly, down-regulation of long-range end resection may cause accumulation of short 3'tail containing DSBs which cannot be channeled to HR repair but is sufficient for exposing microhomologous region nearby DSB site and mediating MMEJ. However, we cannot rule out other possibilities yet. For example, some resection factors may harbor multiple functions. Further, the contradictory results have been obtained in studies of BRCA1, which also is a classical DSB end resection factor. BRCA1 closely associates with MRN complex and CtIP. CDK phosphorylation-mediated interaction between CtIP and BRCA1 enhances the speed of CtIP-mediated end resection [30]. Cell cycle dependent BRCA1-MRN-CtIP complex formation has been reported to play a critical role in DSB end resection and HR-mediated DSB repair in mammalian cells [31]. Early work in DT40 (chicken) B cells suggested that MMEJ is not affected by BRCA1 [32]. While, using different human cells, a recent study indicated BRCA1 may work downstream of Mre11 and CtIP to suppress MMEJ [29]. However, in MEFs cells whose telomeres were artificially uncapped, Madalena Tarsounas's group demonstrated that CtIP and BRCA1 promote MMEJ at uncapped telomeres [33]. Obviously, more accurate systems are needed to clarify the underlining mechanism for the functional relationship between resection factors and MMEJ.

\section{RPA: an old soldier joined new team}

Replication protein A (RPA) is a conserved ssDNA binding protein in eukaryotic cells. RPA is a stable heterotrimer composed of three tightly associated subunits, namely, RPA70, RPA32, and RPA14 encoded by RFA1, RFA2 and RFA3 respectively in Saccharomyces cerevisiae. RPA is involved in almost all aspects of cellular DNA metabolism such as DNA replication, recombination, DNA damage checkpoints, and repair of many types of DNA damage. RPA has been reported to bind to ssDNA with much higher affinity than double strand DNA (dsDNA) or RNA. In vitro, it also harbors dsDNA helix-unwinding activity [34-38]. In budding yeast and human cells, RPA is an important component of DSB end resection machinery in previously described two-step resection model. It works together with Sgs1/DNA2 in yeast or BLM/DNA2 in human cells to promote extensive end resection [23]. After resection, RPA immediately recognizes and coats newly produced $3^{\prime}$-ssDNA tails by its ssDNA binding activity to stabilize ssDNA and recruit Rad51 recombinase. Rad51 recruitment was thought as a crucial step for HR repair initiation [39,
40]. Using a powerful genetic screen system, Deng et al. recently found that depletion of extensive resection factors promotes MMEJ close to the DSB site. The strains with exo1 $\Delta$ sgs $1 \Delta$ background show much higher proximal MMEJ frequency than wild type [16]. Actually, Lan et al. got similar results in mammalian cell using a welldesigned MMEJ and HR competition repair substrate [13], indicating that long distance resection may suppress proximal MMEJ by switching repair pathway to HR. However, using hypomorphic mutant alleles of RFA1 with point mutations in the DNA-binding domain, Deng et al. showed that MMEJ can be dramatically increased without obviously decreased end resection and HR efficiency. In vitro, they also found that RPA mutants were defective in ssDNA binding and secondary structure removing. They thus concluded that RPA is a critical negative regulator of MMEJ. Independent of its end resection and $\mathrm{HR}$ function, ssDNA binding and dsDNA unwinding activities of RPA help it to inhibit MMEJ by preventing spontaneous annealing of microhomogous sequence flanking DSB site (Fig. 2). For the first time, Deng et al. revealed a novel function of RPA in MMEJ repair regulation [16]. Meantime, their data also help us recognize that DSB end resection may not be a rate limiting step for MMEJ although this mechanism always needs end resection to expose microhomologous region. We thus believe that other important regulatory mechanism must be existed to tightly control this error-prone repair mechanism and protect genome stability.

\section{Polø: new focus}

DNA polymerase theta ( $\mathrm{Pol} \theta$, also known as PolQ, encoded by $P O L Q$ ) is a unique A-family DNA polymerase. It contains a helicase-like domain at its $\mathrm{N}$ terminus, which is separated from the C-terminal polymerase domain by a long, unstructured central region (Fig. 3). The helicase-like domain of $\operatorname{Pol} \theta$ is conserved among higher organisms. It shares more than $50 \%$ sequence similarity with human HELQ (also known as HEL308), which possesses dsDNA unwinding activity in vitro. However, up to now, no any strand replacement activity was identified in the helicase-like domain of $\operatorname{Pol} \theta$ either in vivo or in vitro although it showed high level of ssDNA-dependent ATPase activity [41]. The C-terminal polymerase domain of $\operatorname{Pol} \theta$ exhibits highly promiscuous enzyme activity. It exhibits low-fidelity DNA synthesis, translesion synthesis and lyase activity. $\operatorname{Pol} \theta$ also can promote extension of ssDNA and partial ssDNA substrates in an error-prone manner [42-45]. Since it was identified as the product of the $P O L Q$ gene more than 25 years ago, $\operatorname{Pol} \theta$ has been reported to get involved in distinct DNA damage repair pathways in different organisms. However, how its enzymatic activity link to its cellular functions still 


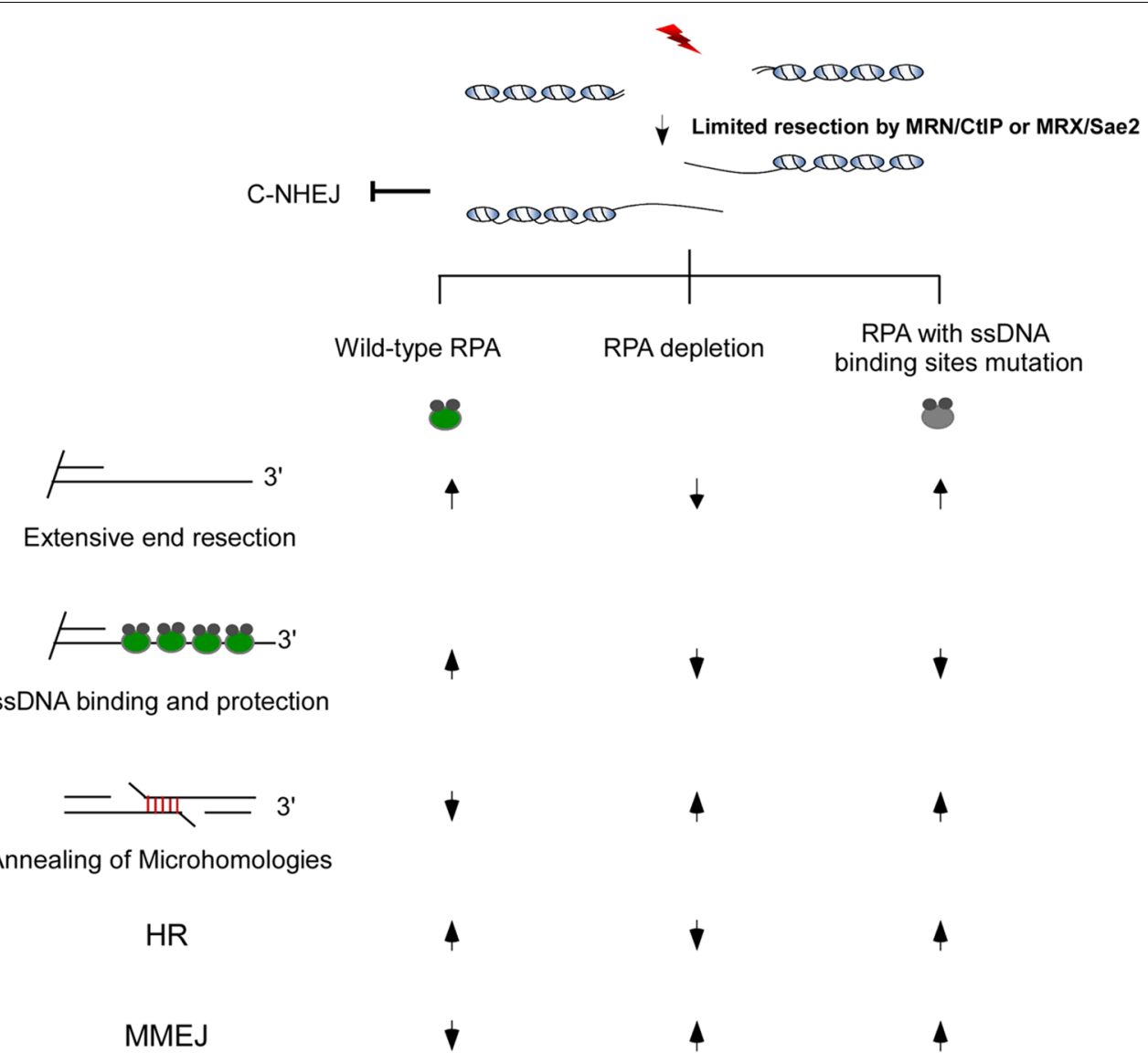

Fig. 2 Functions of RPA and its ssDNA binding defect mutant. Up arrow indicating function is efficient. Down arrow indicating function is deficient

not well understood [46-50]. Recently, several reports emphasized a central role of Pol $\theta$ in MMEJ-mediated DSB repair in higher organisms. Early studies in Drosophila indicated that $\operatorname{Pol} \theta$ promotes I-sceI-induced MMEJ, whereas polq-1 was shown to be required for MMEJ in response to replication-fork collapse at $\mathrm{G}$ quadruplexes in C. elegans $[51,52]$. Recent studies in mice indicated that $\operatorname{Pol} \theta$ is associated with MMEJ-mediated fusions of dysfunctional telomeres and chromosomal translocation. $\operatorname{Pol} \theta$ was recruited to DNA damage sites induced by laser micro-irradiation in a PARP-1 dependent manner and promoted MMEJ in endonuclease-mediated reporter system [15]. Biochemical study revealed that purified human $\operatorname{Pol} \theta$ protein possesses unique MMEJ promotion activity [53]. Pol $\theta$ promotes DNA synapse formation, microhomology annealing and the following synapse stabilization by catalyzing overhang extension, then stimulating MMEJ of DNA substrate containing $3^{\prime}$ ssDNA overhang with more than $2 \mathrm{bp}$ of homology [53] The conserved insertion loop2 domain (L2 domain, Fig. 3) is important for MMEJ activity of Pol $\theta$ both in vitro and in vivo. L2 domain may promote oligomerization of $\operatorname{Pol} \theta$ protein, then driving DNA end synapsis and MMEJ [53]. There are no reports to show whether the helicase-like and central domain of $\mathrm{Pol} \theta$ also directly joined in the MMEJ. However, Ceccaldi et al. identified a Rad51 binding motif in the central part of Pol $\theta$ and demonstrated that ATPase activity and Rad51 binding capacity may help $\operatorname{Pol} \theta$ to block RAD51 nucleofilament assembly and HR activity, thus channelling DSB repair to MMEJ pathway. This suggests that indirect regulatory function of $\operatorname{Pol} \theta$ may also contribute to MMEJ activity.

\section{Concluding remarks}

Increasing evidences suggest that MMEJ may not just be a back-up DSB repair mechanism. MMEJ occurs even when HR and NHEJ are intact and is essential for HR-deficient cancer cells. Therefore, it is well deserved to fully decipher the molecular mechanisms of MMEJ and its unique function in DSB repair. So far, several key factors identified in both MMEJ repair and regulation have overlapping functions with other repair pathways. 


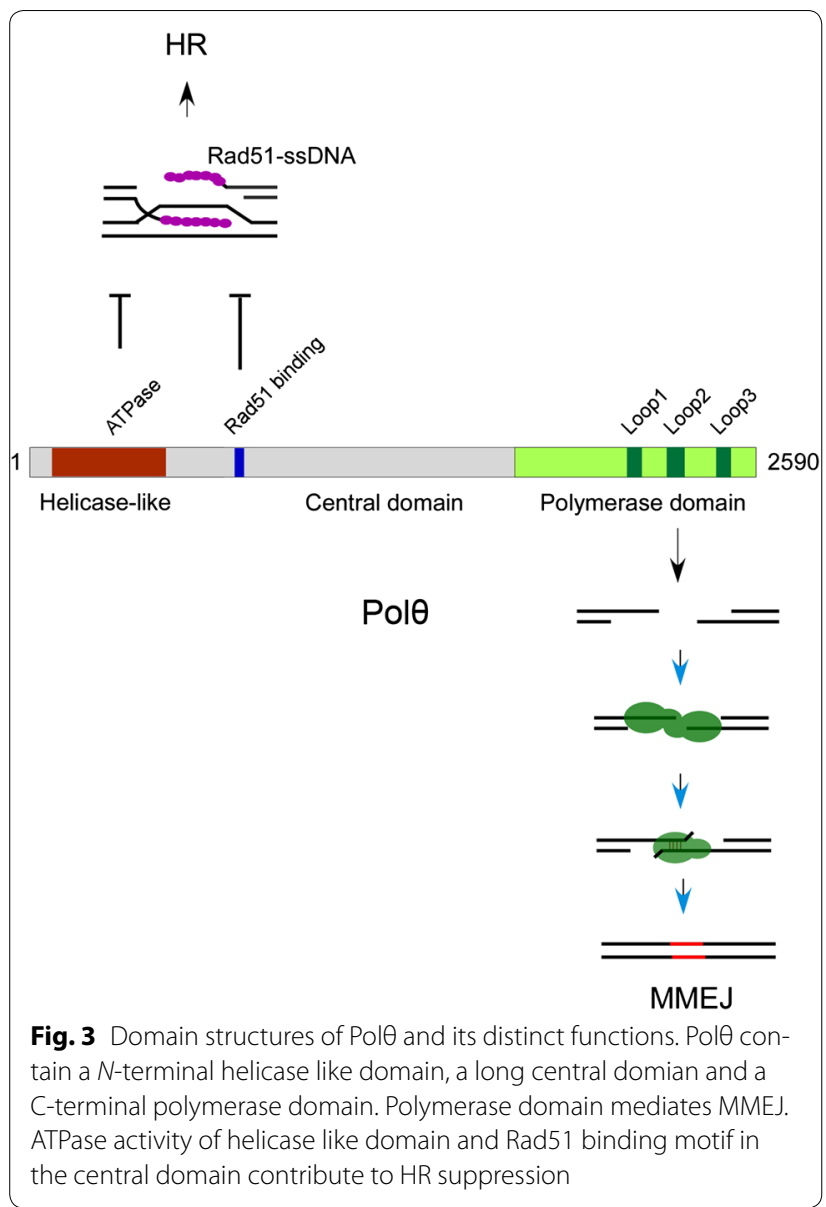

Discovery of specific enzymes or protein factors that solely work in MMEJ repair pathway will help us understand the detail mechanism of MMEJ and its unique role in DSB repair and be instrumental for MMEJ-targeted drug design.

\section{Authors' contributions}

HW and XX planned and critically revised the manuscript. Both authors read and approved the final manuscript.

\section{Acknowledgements}

We thank the members of Xu and Wang lab for helpful discussions. We apologize for that we were not able to cite all the works of our colleagues in this review due to space limitation.

\section{Competing interests}

The authors declare that they have no competing interests.

\section{Funding}

Research in the Hailong Wang's group and Xingzhi Xu's group is supported by the 973 projects 2015CB910601/2 and 2013CB911002; the National Natural Science Foundation of China (NSFC) Grants 31370841, 31530016, and 31461143012; The Importation and Development of High-Caliber Talents Project of Beijing Municipal Institutions (CIT\&TCD201504069).

Received: 25 December 2016 Accepted: 6 January 2017 Published online: 13 January 2017

\section{References}

1. Bassing $\mathrm{CH}$, Alt FW. The cellular response to general and programmed DNA double strand breaks. DNA Repair. 2004;3:781-96.

2. Khanna KK, Jackson SP. DNA double-strand breaks signaling, repair and the cancer connection. Nat Genet. 2001:27:247-54

3. Varon R, Vissinga C, Platzer M, Cerosaletti KM, Chrzanowska KH, Saar K, Beckmann G, Seemanova E, Cooper PR, Nowak NJ, et al. Nibrin, a novel DNA double-strand break repair protein, is mutated in Nijmegen breakage syndrome. Cell. 1998;93:467-76.

4. Stewart GS, Maser RS, Stankovic T, Bressan DA, Kaplan MI, Jaspers NG, Raams A, Byrd PJ, Petrini JH, Taylor AM. The DNA double-strand break repair gene hMRE11 is mutated in individuals with an ataxia-telangiectasia-like disorder. Cell. 1999;99:577-87.

5. Miki Y, Swensen J, Shattuck-Eidens D, Futreal PA, Harshman K, Tavtigian S, Liu Q, Cochran C, Bennett LM, Ding W, et al. A strong candidate for the breast and ovarian cancer susceptibility gene BRCA1. Science. 1994:266:66-71.

6. Lieber MR. The mechanism of double-strand DNA break repair by the nonhomologous DNA end-joining pathway. Annu Rev Biochem. 2010;79:181-211.

7. Moynahan ME, Jasin M. Mitotic homologous recombination maintains genomic stability and suppresses tumorigenesis. Nat Rev Mol Cell Biol. 2010;11:196-207.

8. Symington LS, Gautier J. Double-strand break end resection and repair pathway choice. Annu Rev Genet. 2011;45:247-71.

9. Lin WY, Wilson JH, Lin Y. Repair of chromosomal double-strand breaks by precise ligation in human cells. DNA Repair. 2013;12:480-7.

10. Chiruvella KK, Liang Z, Wilson TE. Repair of double-strand breaks by end joining. Cold Spring Harb Perspec Biol. 2013:5:a012757.

11. Boulton SJ, Jackson SP. Saccharomyces cerevisiae Ku70 potentiates illegitimate DNA double-strand break repair and serves as a barrier to error-prone DNA repair pathways. EMBO J. 1996;15:5093-103.

12. Ma JL, Kim EM, Haber JE, Lee SE. Yeast Mre11 and Rad1 proteins define a Ku-independent mechanism to repair double-strand breaks lacking overlapping end sequences. Mol Cell Biol. 2003:23:8820-8.

13. Truong LN, Li Y, Shi LZ, Hwang PY, He J, Wang H, Razavian N, Berns MW, Wu X. Microhomology-mediated end joining and homologous recombination share the initial end resection step to repair DNA double-strand breaks in mammalian cells. Proc Natl Acad Sci USA. 2013;110:7720-5.

14. Ceccaldi R, Liu JC, Amunugama R, Hajdu I, Primack B, Petalcorin MI, O'Connor KW, Konstantinopoulos PA, Elledge SJ, Boulton SJ, et al. Homologous-recombination-deficient tumours are dependent on Poltheta-mediated repair. Nature. 2015;518:258-62.

15. Mateos-Gomez PA, Gong F, Nair N, Miller KM, Lazzerini-Denchi E, Sfeir A. Mammalian polymerase theta promotes alternative NHEJ and suppresses recombination. Nature. 2015:518:254-7.

16. Deng SK, Gibb B, de Almeida MJ, Greene EC, Symington LS. RPA antagonizes microhomology-mediated repair of DNA double-strand breaks. Nat Struct Mol Biol. 2014;21:405-12.

17. Sfeir A, Symington LS. Microhomology-mediated end joining. A backup survival mechanism or dedicated pathway? Trends Biochem Sci. 2015;40:701-14.

18. Decottignies A. Alternative end-joining mechanisms: a historical perspective. Front Genet. 2013;4:48.

19. McVey M, Lee SE. MMEJ repair of double-strand breaks (director's cut): deleted sequences and alternative endings. Trends Genet. 2008:24:529-38.

20. Pannunzio NR, Li S, Watanabe G, Lieber MR. Non-homologous end joining often uses microhomology: implications for alternative end joining. DNA Repair (Amst). 2014;17:74-80

21. Sinha S, Villarreal D, Shim EY, Lee SE. Risky business. Microhomologymediated end joining. Mutat Res. 2016:788:17-24.

22. Villarreal DD, Lee K, Deem A, Shim EY, Malkova A, Lee SE. Microhomology directs diverse DNA break repair pathways and chromosomal translocations. PLoS Genet. 2012;8:e1003026.

23. Symington LS. End resection at double-strand breaks: mechanism and regulation. Cold Spring Harb Perspect Biol. 2014;6:8.

24. Cejka P, Cannavo E, Polaczek P, Masuda-Sasa T, Pokharel S, Campbell JL, Kowalczykowski SC. DNA end resection by Dna2-Sgs1-RPA and its stimulation by Top3-Rmi1 and Mre11-Rad50-Xrs2. Nature. 2010;467:112-6. 
25. Niu H, Chung WH, Zhu Z, Kwon Y, Zhao W, Chi P, Prakash R, Seong C, Liu D, Lu L, et al. Mechanism of the ATP-dependent DNA end-resection machinery from Saccharomyces cerevisiae. Nature. 2010;467:108-11.

26. Nimonkar AV, Genschel J, Kinoshita E, Polaczek P, Campbell JL, Wyman C, Modrich P, Kowalczykowski SC. BLM-DNA2-RPA-MRN and EXO1-BLMRPA-MRN constitute two DNA end resection machineries for human DNA break repair. Genes Dev. 2011;25:350-62

27. Makharashvili N, Tubbs AT, Yang SH, Wang H, Barton O, Zhou Y, Deshpande RA, Lee JH, Lobrich M, Sleckman BP, et al. Catalytic and noncatalytic roles of the $\mathrm{CtIP}$ endonuclease in double-strand break end resection. Mol Cell. 2014:54:1022-33.

28. Wang H, Li Y, Truong LN, Shi LZ, Hwang PY, He J, Do J, Cho MJ, Li H, Negrete A, et al. CtIP maintains stability at common fragile sites and inverted repeats by end resection-independent endonuclease activity. Mol Cell. 2014;54:1012-21.

29. Ahrabi S, Sarkar S, Pfister SX, Pirovano G, Higgins GS, Porter AC, Humphrey TC. A role for human homologous recombination factors in suppressing microhomology-mediated end joining. Nucleic Acids Res. 2016;44:5743-57.

30. Cruz-Garcia A, Lopez-Saavedra A, Huertas P. BRCA1 accelerates CtIPmediated DNA-end resection. Cell Rep. 2014;9:451-9.

31. Chen L, Nievera CJ, Lee AY, Wu X. Cell cycle-dependent complex formation of BRCA1.CtIP.MRN is important for DNA double-strand break repair. J Biol Chem. 2008;283:7713-20.

32. Yun MH, Hiom K. CtIP-BRCA1 modulates the choice of DNA doublestrand-break repair pathway throughout the cell cycle. Nature. 2009:459:460-3.

33. Badie S, Carlos AR, Folio C, Okamoto K, Bouwman P, Jonkers J, Tarsounas M. BRCA1 and CtIP promote alternative non-homologous end-joining at uncapped telomeres. EMBO J. 2015;34:828.

34. Iftode C, Daniely Y, Borowiec JA. Replication protein A (RPA): the eukaryotic SSB. Crit Rev Biochem Mol Biol. 1999;34:141-80.

35. Lao Y, Lee CG, Wold MS. Replication protein A interactions with DNA. 2. Characterization of double-stranded DNA-binding/helix-destabilization activities and the role of the zinc-finger domain in DNA interactions. Biochemistry. 1999;38:3974-84.

36. Walther AP, Gomes XV, Lao Y, Lee CG, Wold MS. Replication protein A interactions with DNA. 1. Functions of the DNA-binding and zinc-finger domains of the 70-kDa subunit. Biochemistry. 1999;38:3963-73.

37. Georgaki A, Strack B, Podust V, Hubscher U. DNA unwinding activity of replication protein A. F FEBS Lett. 1992;308:240-4.

38. Zou Y, Liu Y, Wu X, Shell SM. Functions of human replication protein A (RPA): from DNA replication to DNA damage and stress responses. J Cell Physiol. 2006;208:267-73.
39. San Filippo J, Sung P, Klein H. Mechanism of eukaryotic homologous recombination. Annu Rev Biochem. 2008;77:229-57.

40. Mimitou EP, Symington LS. Nucleases and helicases take center stage in homologous recombination. Trends Biochem Sci. 2009;34:264-72.

41. Seki M, Marini F, Wood RD. POLQ (Pol theta), a DNA polymerase and DNAdependent ATPase in human cells. Nucleic Acids Res. 2003;31:6117-26.

42. Hogg M, Seki M, Wood RD, Doublie S, Wallace SS. Lesion bypass activity of DNA polymerase theta (POLQ) is an intrinsic property of the pol domain and depends on unique sequence inserts. J Mol Biol. 2011:405:642-52.

43. Arana ME, Seki M, Wood RD, Rogozin IB, Kunkel TA. Low-fidelity DNA synthesis by human DNA polymerase theta. Nucleic Acids Res. 2008:36:3847-56.

44. Harris PV, Mazina OM, Leonhardt EA, Case RB, Boyd JB, Burtis KC. Molecular cloning of Drosophila mus308, a gene involved in DNA cross-link repair with homology to prokaryotic DNA polymerase I genes. Mol Cell Biol. 1996;16:5764-71.

45. Marini F, Wood RD. A human DNA helicase homologous to the DNA cross-link sensitivity protein Mus308. J Biol Chem. 2002;277:8716-23.

46. Boyd JB, Sakaguchi K, Harris PV. mus 308 mutants of Drosophila exhibit hypersensitivity to DNA cross-linking agents and are defective in a deoxyribonuclease. Genetics. 1990;125:813-9.

47. Muzzini DM, Plevani P, Boulton SJ, Cassata G, Marini F. Caenorhabditis elegans POLQ-1 and HEL-308 function in two distinct DNA interstrand cross-link repair pathways. DNA Repair (Amst). 2008;7:941-50.

48. Zan H, Shima N, Xu Z, Al-Qahtani A, Evinger lii AJ, Zhong Y, Schimenti JC, Casali P. The translesion DNA polymerase theta plays a dominant role in immunoglobulin gene somatic hypermutation. EMBO J. 2005;24:3757-69.

49. Masuda K, Ouchida R, Takeuchi A, Saito T, Koseki H, Kawamura K, Tagawa M, Tokuhisa T, Azuma T. J OW. DNA polymerase theta contributes to the generation of $C / G$ mutations during somatic hypermutation of Ig genes. Proc Natl Acad Sci USA. 2005;102:13986-91.

50. Yoshimura M, Kohzaki M, Nakamura J, Asagoshi K, Sonoda E, Hou E, Prasad R, Wilson SH, Tano K, Yasui A, et al. Vertebrate POLQ and POLbeta cooperate in base excision repair of oxidative DNA damage. Mol Cell. 2006;24:115-25.

51. Chan SH, Yu AM, McVey M. Dual roles for DNA polymerase theta in alternative end-joining repair of double-strand breaks in Drosophila. PLoS Genet. 2010;6:e1001005.

52. Yu AM, McVey M. Synthesis-dependent microhomology-mediated end joining accounts for multiple types of repair junctions. Nucleic Acids Res. 2010;38:5706-17.

53. Kent T, Chandramouly G, McDevitt SM, Ozdemir AY, Pomerantz RT. Mechanism of microhomology-mediated end-joining promoted by human DNA polymerase theta. Nat Struct Mol Biol. 2015:22:230-7.

\section{Submit your next manuscript to BioMed Central and we will help you at every step:}

- We accept pre-submission inquiries

- Our selector tool helps you to find the most relevant journal

- We provide round the clock customer support

- Convenient online submission

- Thorough peer review

- Inclusion in PubMed and all major indexing services

- Maximum visibility for your research

Submit your manuscript at www.biomedcentral com/submit
BioMed Central 